\title{
EULAR evidence based recommendations for the management of hip osteoarthritis: report of a task force of the EULAR Standing Committee for International Clinical Studies Including Therapeutics (ESCISIT)
}

\author{
W Zhang, M Doherty, N Arden, B Bannwarth, J Bij|sma, K-P Gunther, \\ H J Hauselmann, G Herrero-Beaumont, K Jordan, P Kaklamanis, B Leeb, \\ $M$ Lequesne, S Lohmander, B Mazieres, E Martin-Mola, K Pavelka, \\ A Pendleton, L Punzi, B Swoboda, R Varatojo, G Verbruggen, \\ I Zimmermann-Gorska, M Dougados
}

Appendixes are available on the website at http:// www.annrheumdis.com/ supplemental

See end of article for authors' affiliations

Correspondence to: Professor M Dougados, Institute of Rheumatology, 27, rue du Faubourg, Saint Jacques, 71054 Paris, France;

maxime.dougados@ cch.ap-hop-paris.fr

Accepted

1 September 2004

Published Online First

7 October 2004

\begin{abstract}
Objective: To develop evidence based recommendations for the management of hip osteoarthritis (OA). Methods: The multidisciplinary guideline development group comprised 18 rheumatologists, 4 orthopaedic surgeons, and 1 epidemiologist, representing 14 European countries. Each participant contributed up to 10 propositions describing key clinical aspects of hip OA management. Ten final recommendations were agreed using a Delphi consensus approach. Medline, Embase, CINAHL, Cochrane Library, and HTA reports were searched systematically to obtain research evidence for each proposition. Where possible, outcome data for efficacy, adverse effects, and cost effectiveness were abstracted. Effect size, rate ratio, number needed to treat, and incremental cost effectiveness ratio were calculated. The quality of evidence was categorised according to the evidence hierarchy. The strength of recommendation was assessed using the traditional $A-D$ grading scale and a visual analogue scale. Results: Ten key treatment propositions were generated through three Delphi rounds. They included 21 interventions, such as paracetamol, NSAIDs, symptomatic slow acting disease modifying drugs, opioids, intra-articular steroids, non-pharmacological treatment, total hip replacement, osteotomy, and two general propositions. 461 studies were identified from the literature search for the proposed interventions of efficacy, side effects, and cost effectiveness. Research evidence supported 15 interventions in the treatment of hip OA. Evidence specific for the hip was strikingly lacking. Strength of recommendation varied according to category of research evidence and expert opinion.

Conclusion: Ten key recommendations for the treatment of hip OA were developed based on research evidence and expert consensus. The effectiveness and cost effectiveness of these recommendations were evaluated and the strength of recommendation was scored.
\end{abstract}

$\mathrm{T}$ he hip is the second most common large joint to be affected by osteoarthritis (OA). The prevalence of hip OA ranges from 3 to $11 \%$ in Western populations aged over 35 years. ${ }^{1-5}$ It is often associated with significant pain, disability, and impaired quality of life. Although available treatments for hip and knee OA are similar and include pharmacological, non-pharmacological, and surgical options, there are certain differences. Furthermore, the effect size of a specific treatment might vary according to the site of the OA involvement, owing to differences in anatomy, biomechanics, risk factors for development and progression, and accessibility to local treatments. Therefore, having developed evidence based recommendations for the management of knee OA, ${ }^{67}$ the EULAR OA Task Force next focused on a parallel document to consider the treatment of hip OA. As before, ${ }^{67}$ recommendations were developed using a Delphi consensus approach and assessed both by current available research evidence and expert opinion.

\section{METHODS}

\section{Participants}

A multidisciplinary guideline development committee was commissioned by ESCISIT. Twenty three experts in the field of OA (18 rheumatologists, 4 orthopaedic surgeons, and 1 epidemiologist) representing 14 European countries agreed to take part in the study. The objectives were $(a)$ to agree 10 key propositions for the management of hip OA; $(b)$ to identify and critically appraise research evidence for the effectiveness

Abbreviations: ASU, avocado soybean unsaponifiable; $\mathrm{Cl}$, confidence interval; COX-2, cyclo-oxygenase-2; CS, chondroitin sulphate; CT, controlled trial; $\mathrm{CV}$, cardiovascular; $\mathrm{ES}$, effect size; GI, gastrointestinal; GS, glucosamine sulphate; HA, hyaluronic acid; ICER, incremental cost effectiveness ratio; NNT, number needed to treat; NSAIDs, non-steroidal anti-inflammatory drugs; QALY, quality of life year; OA, osteoarthritis;

$\mathrm{OR}$, odds ratio; PPI, proton pump inhibitor; $\mathrm{RCT}$, randomised controlled trial; RR, relative risk; SYSADOA, symptomatic slow acting drugs for OA; THR, total hip replacement; VAS, visual analogue scale 
Table 1 Evidence hierarchy and traditional strength of recommendation

\begin{tabular}{ll}
\hline Category of evidence & Strength of recommendation \\
\hline $\begin{array}{l}\text { la Meta-analysis of RCTs } \\
\text { Ib RCT }\end{array}$ & A Category I evidence \\
Ila Controlled study without randomisation & B Category II evidence or extrapolated from \\
category I evidence
\end{tabular}

and cost effectiveness of the relevant treatments; and (c) to generate recommendations based on a combination of the best available evidence and expert opinion.

\section{Experts' consensus}

Each committee member was asked to contribute independently up to 10 propositions describing key clinical interventions for OA of the hip. Consensus on the propositions was reached using the Delphi technique. The initial propositions were collated into a single list. Similar, overlapping propositions were combined. The list was returned to the experts and they were asked to select the 10 most important from the list. Propositions were accepted automatically if selected by over half of participants in any round, whereas propositions receiving only one to three votes were removed. Propositions receiving less than $50 \%$ of the votes but more than three votes entered the next Delphi round. The procedure was repeated until 10 propositions were agreed.

\section{Systematic literature search}

A systematic search of the literature published between January 1966 and March 2004 was undertaken using Medline, Embase, CINHAL, and Cochrane Library databases. The search included both a general search and an intervention-specific search. The general search strategy consisted of two basic components: hip OA in whatever possible terms in the databases (Appendix l, available at http://www. annrheumdis.com/supplemental) and types of research in the forms of systematic review/meta-analysis, randomised controlled trial (RCT)/controlled trial (CT), uncontrolled trial, cohort study, case-control study, cross sectional study, and economic evaluation (Appendix 2, available at http:// www.annrheumdis.com/supplemental). The general search aimed at summarising the current available reported treatments for hip OA. The summary results of this search were reported to the committee before the Delphi exercise.

After the Delphi exercise had generated the 10 propositions, the intervention-specific search was undertaken to identify evidence for each specific intervention. The search strategy included the terms for hip OA (Appendix l, http:// www.annrheumdis.com/supplemental) and any possible terms for the specific intervention. For example paracetamol, acetaminophen, or simple analgesics were used for paracetamol. The results of the two searches were then combined and duplications excluded. Medical subject heading search (MeSH) was used for all databases and a keyword search was used if the MeSH search was not available. All MeSH search terms were exploded. The reference lists within reviews or systematic reviews were examined and any additional studies meeting the inclusion/exclusion criteria were included.

The search in the Cochrane Library included MeSH search of the Cochrane Review, Abstracts of Quality Assessed Systematic Reviews, the Cochrane Controlled Trial Register,
NHS Economic Evaluation Databases, the Health Technology Assessment Database, and NHS Economic Evaluation Bibliography Details only. In addition, a topics search on OA was undertaken.

\section{Inclusion/exclusion criteria}

Only studies with clinical outcomes for hip OA were included. The main focus of interest was on systematic reviews, RCTs/CTs, uncontrolled trials/cohort studies, casecontrol studies, cross sectional studies, and economic evaluations. Studies that combined hip and knee (and/or other joint) OA were excluded unless the results for patients with hip OA were reported separately. Studies of other sites of OA or other chronic joint conditions were excluded unless the adverse effects were investigated as a primary outcome. Other exclusions were case reports, animal studies, nonclinical outcome studies, narrative review articles, commentaries, and guidelines.

\section{Categorising evidence}

Evidence was categorised according to study design using a hierarchy of evidence in descending order according to qualities $^{8}$ (table 1). Questions on efficacy were answered using the best available evidence. For example, if a question on the effect of an intervention could be answered by category Ia evidence (that is, a systematic review of RCTs) then studies of a weaker design (RCTs, category Ib) were not reviewed. Questions on side effects were answered using both RCTs and observational studies. Although the efficacy was assessed specifically for hip OA, side effects were evaluated specifically for the intervention irrespective of the musculoskeletal condition. Questions on cost effectiveness were answered according to the outcome measure of the effectiveness. For example, if the effectiveness was measured as pain relief or quality of life years (QALYs) gained, only studies for hip OA were eligible. If the effectiveness was measured as adverse events averted, any studies for the proposed interventions were included.

\section{Estimation of effectiveness and cost effectiveness}

Effect size (ES) and 95\% confidence interval (95\% CI) compared with placebo or active control as specified within the propositions was calculated for continuous outcomes such as pain relief and improvement in function. ${ }^{9}$ The ES is the standard mean difference-that is, the mean difference between a treatment and a control group, divided by the standard deviation of the difference. It therefore has no units and is comparable across the interventions. Clinically, $\mathrm{ES}=0.2$ is considered small, $\mathrm{ES}=0.5$ is moderate, and ES $>0.8$ is large. ${ }^{10}$ Results from the latest systematic review were used if more than one systematic review was available for the same intervention. Statistical pooling was undertaken as appropriate ${ }^{11}$ when a systematic review was not available. 


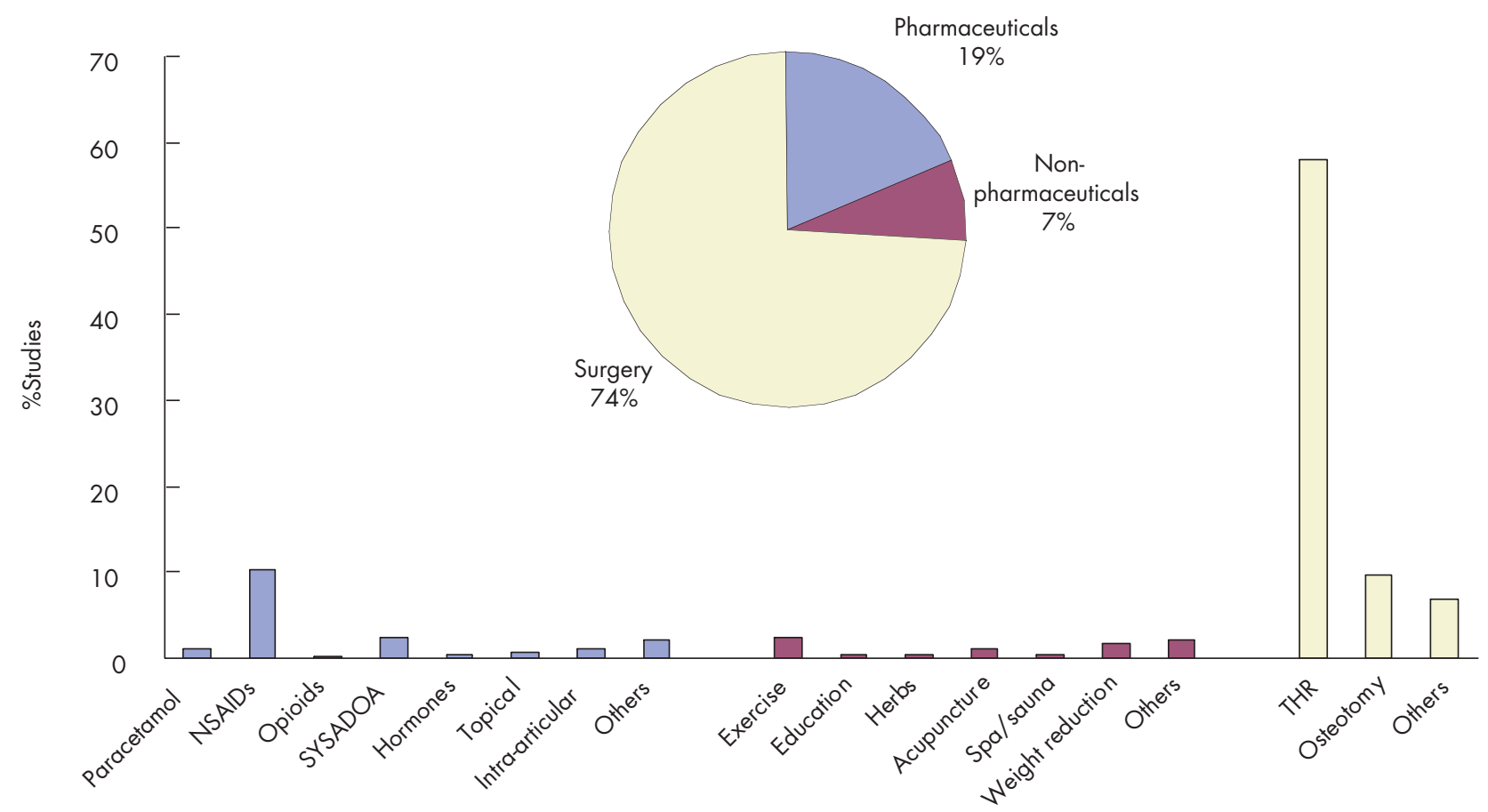

Figure 1 Interventions for hip osteoarthritis from the general literature search. SYSADOA, symptomatic slow acting drugs for OA; THR, total hip replacement.

The percentage of patients with moderate to excellent (or $>50 \%$ ) pain relief or symptomatic improvement was calculated and the number needed to treat (NNT) was estimated. ${ }^{12}$ A positive value for the NNT means the treatment is more beneficial than control; whereas a negative value for the NNT means the treatment is less beneficial than control. NNT and 95\% CI were reported only if it was statistically significant; otherwise "NS" (not significant) was used to avoid the

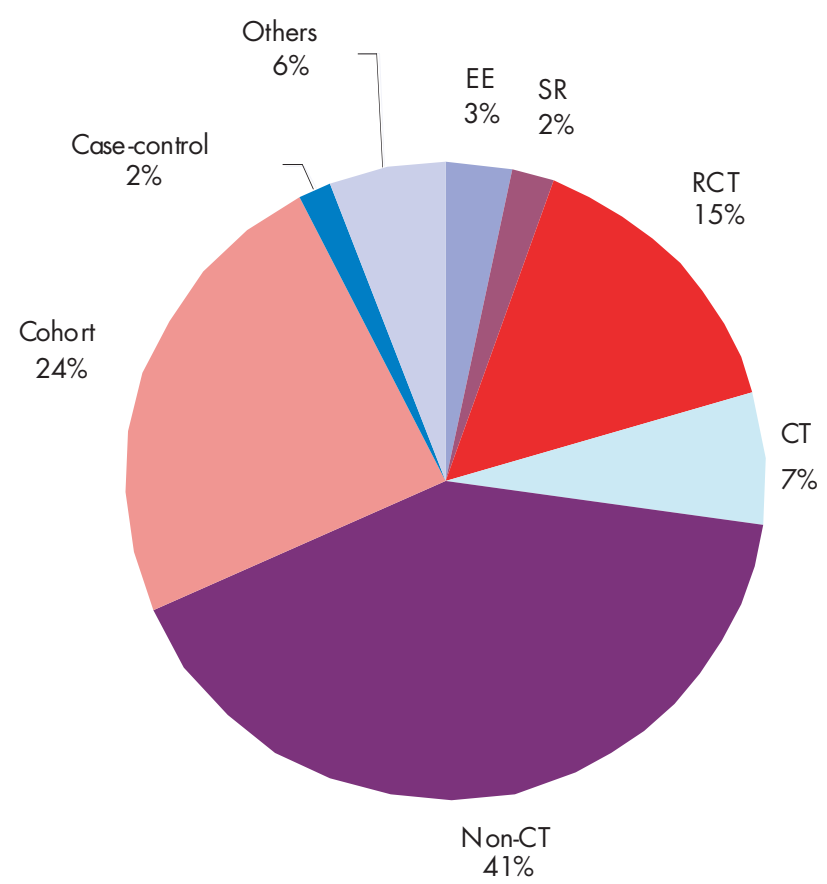

Figure 2 Study designs for hip OA from the general literature search. $\mathrm{EE}$, economic evaluation; SR, systematic review; RCT, randomised controlled trial; CT, controlled trial. confusion due to its unique mathematical features. ${ }^{13}$ Relative risk (RR) was calculated for adverse effects. ${ }^{14}$

When economic evaluation was available, study design, comparator, perspective, time horizon, discounting, total costs, effectiveness were reviewed. The incremental cost effectiveness ratio (ICER) was calculated. QALYs were used when available, otherwise disease-specific outcomes such as pain relief and functional improvement were used.

Data were extracted by two investigators using a customised form. Any discrepancies were discussed and agreed between the extractors before analysis. Non-English language studies were extracted by the native investigators.

\section{Strength of recommendation}

The strength of recommendation was graded A-D based on the category of efficacy evidence (table 1$)^{8}$ by two members of the committee (WZ, MD) and subsequently ratified by the committee. When hip-specific data were absent and therefore no hip-specific category was applicable, no strength of recommendation could be applied. However, a visual analogue scale (VAS) was also used. Each member of the committee was asked to mark on a $0-100 \mathrm{~mm}$ VAS their strength of recommendation for each intervention, according to the research evidence (efficacy, safety, and cost effectiveness) and clinical expertise (logistics, patient perceived acceptance and tolerability). The means and standard error of the mean (SEM) for the strength of recommendation were calculated for each intervention. This system allowed strength of recommendation to be applied when hip-specific efficacy data were absent.

\section{Future research agenda}

Each committee member was asked to propose 10 topics for the future research agenda based on current available evidence and clinical experience in the management of hip OA. A Delphi approach was used to reach a consensus on the 10 most important topics. The same criteria as those used to select propositions were employed (that is, accepted when 
Table 2 Experts' propositions developed through three Delphi rounds - order according to topic (general, non-pharmacological, pharmacological, invasive and surgical)

\begin{tabular}{|c|c|}
\hline No & Proposition \\
\hline 1 & $\begin{array}{l}\text { Optimal management of hip OA requires a combination of non-pharmacological and pharmacological } \\
\text { treatment modalities }\end{array}$ \\
\hline 2 & $\begin{array}{l}\text { Treatment of hip OA should be tailored according to: } \\
\text { (a) Hip risk factors (obesity, adverse mechanical factors, physical activity, dysplasia) } \\
\text { (b) General risk factors (age, sex, comorbidity, co-medication) } \\
\text { (c) Level of pain intensity, disability, and handicap } \\
\text { (d) Location and degree of structural damage } \\
\text { (e) Wishes and expectations of the patient }\end{array}$ \\
\hline 3 & $\begin{array}{l}\text { Non-pharmacological treatment of hip OA should include regular education, exercise, appliances (stick, } \\
\text { insoles), and weight reduction if obese or overweight }\end{array}$ \\
\hline 4 & $\begin{array}{l}\text { Because of its efficacy and safety paracetamol (up to } 4 \mathrm{~g} / \text { day) is the oral analgesic of first choice for mild- } \\
\text { moderate pain and, if successful, is the preferred long term oral analgesic }\end{array}$ \\
\hline 5 & $\begin{array}{l}\text { NSAIDs, at the lowest effective dose, should be added or substituted in patients who respond } \\
\text { inadequately to paracetamol. In patients with increased gastrointestinal risk, non-selective NSAIDs plus a } \\
\text { gastroprotective agent, or a selective COX-2 inhibitor (coxib) should be used }\end{array}$ \\
\hline 6 & $\begin{array}{l}\text { Opioid analgesics, with or without paracetamol, are useful alternatives in patients in whom NSAIDs, } \\
\text { including COX-2 selective inhibitors (coxibs), are contraindicated, ineffective, and/or poorly tolerated }\end{array}$ \\
\hline 7 & $\begin{array}{l}\text { SYSADOA (glucosamine sulphate, chondroitin sulphate, diacerhein, avocado soybean unsaponifiable, } \\
\text { and hyaluronic acid) have a symptomatic effect and low toxicity, but effect sizes are small, suitable } \\
\text { patients are not well defined, and clinically relevant structure modification and pharmacoeconomic } \\
\text { aspects are not well established }\end{array}$ \\
\hline 8 & $\begin{array}{l}\text { Intra-articular steroid injections (guided by ultrasound or } x \text { ray) may be considered in patients with a flare } \\
\text { that is unresponsive to analgesic and NSAIDs }\end{array}$ \\
\hline 9 & $\begin{array}{l}\text { Osteotomy and joint preserving surgical procedures should be considered in young adults with } \\
\text { symptomatic hip } \mathrm{OA} \text {, especially in the presence of dysplasia or varus/valgus deformity }\end{array}$ \\
\hline 10 & $\begin{array}{l}\text { Joint replacement has to be considered in patients with radiographic evidence of hip OA who have } \\
\text { refractory pain and disability }\end{array}$ \\
\hline
\end{tabular}

OA, osteoarthritis; NSAIDs, non-steroidal anti-inflammatory drugs; COX-2, cyclo-oxygenase-2; SYSADOA, symptomatic slow acting drugs for osteoarthritis.

more than 50\% votes; removed when less than three votes; entered into the next round when less than $50 \%$ but more than three votes).

\section{RESULTS}

Treatment modalities and types of research evidence The general search yielded 1725 hits (Medline 1143, Embase 357, CINAHL 46, and Cochrane 179). After deleting duplications, 1341 hits remained. Of these, 898 were original studies and 443 were narrative reviews, commentary, or editorials. Figure 1 shows the breakdown of interventions among the original 898 studies and fig 2 shows the types of evidence.

\section{Experts' opinion approach}

The experts were informed of the results of the general literature search and then the Delphi exercise was undertaken. One hundred and twelve propositions were produced initially and the 10 final propositions were agreed after three anonymous Delphi rounds (table 2).

\section{Assessment of propositions}

The results from the intervention-specific search were merged with the results from the general search. After deleting the duplications and articles irrelevant to the questions, 461 studies remained on the list. These included 44 concerning paracetamol; 287 associated with conventional non-steroidal anti-inflammatory drugs (NSAIDs), cyclooxygenase-2 (COX-2) selective inhibitors (coxibs), and gastroprotective agents; 41 in relation to symptomatic slow acting drugs for OA (SYSADOA); 26 concerning opioid analgesics; 7 for intra-articular steroid injection; 22 related to non-pharmacological treatments; and 34 relevant to the two surgical propositions. The following propositions are grouped by topic (general, non-pharmacological, pharmacological, invasive and surgical) with no weighting according to order.

\section{The optimal management of hip OA requires a} combination of non-pharmacological and pharmacological treatment modalities

Although this statement is logical and represents common clinical practice, there are no direct comparisons or evidence from appropriately designed clinical trials using a factorial design to support this statement. The statement is supported by expert opinion alone (category IV).

\section{The treatment of hip OA should be tailored according to:}

- Hip risk factors (obesity, adverse mechanical factors, physical activity, dysplasia)

- General risk factors (age, sex, comorbidity, co-medication)

- Level of pain intensity, disability, and handicap

- Location and degree of structure damage

- Wishes and expectations of the patient

This statement represents ideal practice and includes clinical markers that are often used to guide clinical decisions. However, although it has considerable commonsense face validity, there is little experimental evidence to support it. RCTs predominantly investigate the efficacy of one or two 
Table 3 Evidence of efficacy-pooled effect size (ES) and number needed to treat (NNT)

\begin{tabular}{|c|c|c|c|c|c|c|}
\hline \multirow[b]{2}{*}{ Intervention } & \multicolumn{3}{|l|}{ Studies } & \multirow[b]{2}{*}{$\mathrm{ES}_{\text {pain }}(95 \% \mathrm{Cl})$} & \multirow[b]{2}{*}{$\mathrm{ES}_{\text {function }}(95 \% \mathrm{Cl})$} & \multirow[b]{2}{*}{ NNT $(95 \% \mathrm{Cl})$} \\
\hline & Category* & No & Duration & & & \\
\hline Education & $\mathrm{lb}$ & 1 & 24 months & - & - & - \\
\hline Weight loss & III & 12 & - & - & - & - \\
\hline NSAIDs & la & 14 & $1-20$ weeks & $0.69(0.12$ to 1.26$)$ & - & $4(3$ to 6$)$ \\
\hline Opioids & $\mathrm{lb}$ & 1 & 4 weeks & $0.78(0.38$ to 1.18$)$ & $0.78(0.26$ to 1.30$)$ & NS \\
\hline Chondroitin sulphate & $\mathrm{lb}$ & 1 & 6 months & - & - & - \\
\hline $\begin{array}{l}\text { Avocado soybean } \\
\text { unsaponifiable }\end{array}$ & $\mathrm{lb}$ & 2 & 6-12 months & $0.31(-0.64$ to 1.26$)$ & $0.52(-0.36$ to 1.40$)$ & - \\
\hline Diacerhein & $\mathrm{lb}$ & 1 & 3 years & $0.00(-0.17$ to 0.17$)$ & $0.00(-0.17$ to 0.17$)$ & - \\
\hline Hyaluronic acid & III & 3 & $3-12$ months & - & $\begin{array}{lll}- & 0 \\
- & 0\end{array}$ & - \\
\hline Intra-articular steroid & $\mathrm{lb}$ & 1 & 3 months & - & - & NS \\
\hline Osteotomy & III & 9 & $2-20$ years & - & - & - \\
\hline THR & III & 118 & $2-20$ years & - & - & - \\
\hline
\end{tabular}

*See table 1 for definitions.

No, number of studies; ES, effect size of treatment compared with placebo unless otherwise stated; NNT, number needed to treat to obtain moderate to excellent $(>50 \%$ ) pain relief or symptomatic improvement; -, not available; NS, not significant.

specific monotherapies in highly selected homogeneous populations of otherwise fit subjects with hip OA. The evidence obtained from such experimental studies therefore may not be directly applicable to the whole population of subjects with hip OA. In addition, because of exclusion of many variables that may influence outcome it is often difficult to determine predictors of outcome. Therefore, better evidence may be obtained from observational studies, such as the large number of cohort studies undertaken to observe possible risk factors or predictors at baseline for total hip replacement (THR) or osteotomy. For example, age, level of dysplasia, and degree of deformity are major predictors for osteotomy, ${ }^{15}{ }^{16}$ and pain intensity, radiographic severity, and degree of disability are associated with clinical outcomes of THR. ${ }^{17-22}$ These factors become even more critical when one moves on to consider the assessment of cost effectiveness. For example, selective COX-2 inhibitors are only cost effective for patients with greater risk of gastrointestinal (GI) bleeding, and THR is more cost effective for younger women. Any management plan requires consideration of patient beliefs and expectations and a holistic approach that takes into account comorbidity and other treatment requirements. Clearly the patient's beliefs and desire for a treatment are likely to be a key component in the clinical decision for THR. $^{23} 24$

In conclusion, this statement reflects the reality of clinical practice and a professional thoughtful approach to the patient. A number of observational studies and economic evaluations provide evidence to support its application (category III).

\section{Non-pharmacological treatment of hip OA should include regular education, exercise, appliances (stick, insoles) and weight reduction if obese or overweight}

Two systematic reviews have been undertaken for education, ${ }^{25}{ }^{26}$ but neither of them contains subgroup data for hip OA. Both show non-statistically significant effects for an education programme compared with control. The ES from the one covering more trials was 0.15 (95\% CI -0.43 to 1.18 ) and -0.02 (95\% CI -0.51 to 0.47$)$ for pain relief and functional improvement, respectively. ${ }^{25}$ One 24 month open RCT was undertaken in patients with hip OA awaiting THR. All patients were given the usual information and an information leaflet before randomisation. They were then assigned randomly to two groups: group 1 attended a collective multidisciplinary information session 2-6 weeks before surgery and group 2 did not and acted as a control. The results showed that the patients receiving education had less pain than the control group. ${ }^{27}$

Five systematic reviews have been undertaken for exercise, ${ }^{28-32}$ but again none of them are specific for the hip. The latest one with the most RCTs provided an ES of 0.39 (95\% CI 0.30 to 0.47 ) for pain relief and an ES of 0.31 (95\% CI 0.23 to 0.39 ) for functional improvement. There is no RCT evidence for the benefits of weight loss. However, one systematic review of observational studies ( 1 cohort and 11 case-control studies) on obesity and risk of hip OA demonstrated that there was a positive relationship between obesity and hip OA in the case-control studies (odds ratio $(\mathrm{OR})=2.3,95 \%$ CI 1.2 to 4.4 ) but not in the cohort study ( $R R=1.03,95 \%$ CI 0.40 to 2.60). ${ }^{33}$ To determine whether exercise has an effect on weight reduction, which in turn might improve clinical outcome for patients with hip OA, further evidence is needed. There is no research evidence for appliances such as stick and insoles for hip OA, although they may help to reduce the adverse forces across the joint.

In summary, only one RCT (category $\mathrm{Ib}$ ) has been undertaken for education in hip OA alone and it suggests that education reduces pain. However, evidence (category Ia) for $\mathrm{OA}$ at any joint showed that education may have very little value and may not reach statistical significance. In contrast, although direct evidence for hip OA is lacking, exercise appears to be beneficial for OA of any kind (category Ia). There is some evidence to support the benefit of weight reduction for hip OA (category III), but no evidence for appliances (stick and insoles) (table 3). Nevertheless, despite the absence of trial data, interventions that reduce adverse mechanical forces across a compromised hip joint have obvious face validity.

4. Because of its efficacy and safety paracetamol (up to $4 \mathrm{~g}$ /day) is the oral analgesic of first choice for mild-moderate pain and, if successful, is the preferred long term oral analgesic

There have been no placebo controlled RCTs, and no comparative efficacy studies in hip OA alone, although paracetamol is widely prescribed for hip OA. Three systematic reviews were identified. ${ }^{33}{ }^{34} 35$ The most recent covered four placebo controlled trials, of which two were undertaken in patients with hip or knee OA over a 6 week period. ${ }^{35}$ The effect size for pain relief was 0.21 (95\% CI 0.02 to 0.41$)$ and the NNT to obtain clinical benefit, defined as moderate to excellent pain relief from paracetamol over placebo, was 4 ( $95 \%$ CI 2 to 43). However, paracetamol was inferior to, but safer than, NSAIDs. 
Table 4 Evidence of safety-pooled relative risk $\left(\mathrm{RR}^{*}\right)$ and $95 \%$ confidence interval $(\mathrm{Cl})$

\begin{tabular}{|c|c|c|c|}
\hline Interventiont & Adverse events & $\operatorname{RR}(95 \% \mathrm{Cl})$ & Category of evidence \\
\hline Paracetamol & $\begin{array}{l}\text { Gl discomfort } \\
\text { Gl perforation/bleed } \\
\text { GI bleeding } \\
\text { Renal failure } \\
\text { Renal failure }\end{array}$ & $\begin{array}{l}0.80(0.27 \text { to } 2.37) \\
3.60(2.60 \text { to } 5.10) \\
1.2(0.8 \text { to } 1.7) \\
0.83(0.50 \text { to } 1.39) \\
2.5(1.7 \text { to } 3.6)\end{array}$ & $\begin{array}{l}\text { RCTs } \\
\text { Case-control study } \\
\text { Case-control studies } \\
\text { Cohort study } \\
\text { Case-control study }\end{array}$ \\
\hline NSAIDs & $\begin{array}{l}\text { GI perforation/ulcer/bleed } \\
\text { Gl perforation/ulcer/bleed } \\
\text { GI perforation/ulcer/bleed }\end{array}$ & $\begin{array}{l}5.36(1.79 \text { to } 16.10) \\
2.70(2.10 \text { to } 3.50) \\
3.00(2.70 \text { to } 3.70)\end{array}$ & $\begin{array}{l}\text { RCTs } \\
\text { Cohort studies } \\
\text { Case-control studies }\end{array}$ \\
\hline Coxibs $v$ NSAIDs & $\begin{array}{l}\text { Endoscopic GI ulcer } \\
\text { CV events }\end{array}$ & $\begin{array}{l}0.18(0.14 \text { to } 0.23) \\
0.79(0.40 \text { to } 1.55)\end{array}$ & $\begin{array}{l}\text { RCTs } \\
\text { RCTs }\end{array}$ \\
\hline Coxibs $v$ naproxen & CV events & 1.69 (1.07 to 2.69$)$ & RCTs \\
\hline Misoprostol & $\begin{array}{l}\text { Endoscopic GI ulcer } \\
\text { Diarrhoea }\end{array}$ & $\begin{array}{l}0.26(0.17 \text { to } 0.39) \\
1.81(1.52 \text { to } 2.16)\end{array}$ & $\begin{array}{l}\text { RCTs } \\
\text { RCTs }\end{array}$ \\
\hline $\mathrm{H}_{2}$ Blockers (double doses) & Endoscopic GI ulcer & $0.44(0.03$ to 0.74$)$ & $\mathrm{RCTs}$ \\
\hline PPls & Endoscopic Gl ulcer & $0.40(0.32$ to 0.51$)$ & RCTs \\
\hline $\begin{array}{l}\text { Opioids+paracetamol } v \\
\text { paracetamol }\end{array}$ & GI upset/constipation & $14.00(1.86$ to 105.16$)$ & $\mathrm{RCT}$ \\
\hline Diacerhein & $\begin{array}{l}\text { Diarrhoea } \\
\text { Skin rash/pruritus }\end{array}$ & $\begin{array}{l}3.73(2.61 \text { to } 5.32) \\
2.40(1.01 \text { to } 5.69)\end{array}$ & $\begin{array}{l}\mathrm{RCT} \\
\mathrm{RCT}\end{array}$ \\
\hline \multicolumn{4}{|c|}{$\begin{array}{l}\text { *RR, relative risk between treatment group and control group; } R R=1 \text {, no different from the control population } \\
\mathrm{RR}>1 \text {, more risky than the control population; } \mathrm{RR}<1 \text {, less risky than the control population. Pooled RR was } \\
\text { estimated for more than one study; tcompared with placebo/non-exposure unless otherwise stated. } \\
\mathrm{H}_{2} \text { Blockers, histamine type } 2 \text { receptor antagonists; PPls, proton pump inhibitors; GI, gastrointestinal; CV, } \\
\text { cardiovascular; CNS, central nervous system. }\end{array}$} \\
\hline
\end{tabular}

Recently, concern has been raised over the possible GI toxicity of paracetamol. One case-control study indicated that paracetamol taken at a dose of more than $2 \mathrm{~g}$ daily was associated with a greater risk of GI perforation or bleed $(\mathrm{OR}=3.6,95 \%$ CI 2.6 to 5.1$),{ }^{36}$ and one cohort study reported a dose-response relationship between paracetamol and dyspepsia. ${ }^{37}$ However, evidence from a systematic review of RCTs shows that paracetamol has no more GI upsets than placebo $(\mathrm{RR}=0.80,95 \% \mathrm{CI} 0.27$ to 2.37$) .{ }^{35}$ A meta-analysis of case-control studies also showed no increased risk of GI bleeding with paracetamol 2-4 g daily ( $\mathrm{OR}=1.2,95 \%$ CI 0.8 to 1.7) and no dose dependent effect in the range of $<2 \mathrm{~g}$, 2-4 g, and $>4 \mathrm{~g}$ per day, ${ }^{38}$ an observation that fits with endoscopic studies. ${ }^{39-41}$
Although there are some concerns about renal toxicity of long term regular use of paracetamol, ${ }^{42}$ evidence to support this is sparse $^{43-45}$ (table 4).

In conclusion, there is no direct evidence to support the use of paracetamol in hip OA. However, evidence in OA of any site (category Ia) demonstrates that paracetamol is effective in relieving pain arising from OA. Although it is inferior to conventional NSAIDs, it is safer when taken within the recommended dose range. There are no long term data on the efficacy or safety of paracetamol and no direct evidence for its cost effectiveness in the treatment of hip OA. However, a study in knee OA shows that paracetamol is better than NSAIDs, NSAIDs plus gastroprotective agents, and coxibs for the cost of each GI adverse effect avoided ${ }^{46}$ (table 5).

Table 5 Evidence of cost effectiveness for the proposed interventions

\begin{tabular}{|c|c|c|c|c|c|c|c|c|}
\hline Intervention & Comparator & Perspective & Duration & Discounting & Effectiveness & $\mathrm{Cl}-\mathrm{C} 2$ & E1-E2 & ICER \\
\hline \multirow[t]{4}{*}{ Paracetamol } & Ibuprofen & Institutional/payer & 6 months & No & PUB averted & $\$ 63000-112000$ & $995-980$ & -3182 \\
\hline & Rofecoxib & Institutional/payer & 6 months & No & PUB averted & $\$ 63000-471000$ & $995-991$ & -99512 \\
\hline & Celecoxib & Institutional/payer & 6 months & No & PUB averted & $\$ 63000-474000$ & $995-990$ & -89347 \\
\hline & Ibuprofen $+\mathrm{Gl}$ protector & Institutional/payer & 6 months & No & PUB averted & $\$ 63000-556000$ & $995-988$ & -68472 \\
\hline \multirow[t]{2}{*}{ Rofecoxib } & Ibuprofen & Institutional/payer & 6 months & No & PUB averted & $\$ 471000-112000$ & $991-980$ & 31770 \\
\hline & NSAIDs & Institutional/payer & 1 year & $3 \%$ & PUB averted & - & - & 4738 \\
\hline Celecoxib & Ibuprofen & Institutional/payer & 6 months & No & PUB averted & $\$ 474000-112000$ & $990-980$ & 33518 \\
\hline Ibuprofen+GI protector & Ibuprofen & Institutional/payer & 6 months & No & PUB averted & $\$ 556000-112000$ & $988-980$ & 54146 \\
\hline $\begin{array}{l}\text { NSAIDs+misoprostol (all } \\
\text { patients with OA) }\end{array}$ & NSAIDs & Canadian Health services & 3 months & No & PUB averted & $\$ 32396-25622$ & $96-86$ & 684 \\
\hline $\begin{array}{l}\text { NSAIDs+misoprostol (patients } \\
\text { with OA aged } \geqslant 65 \text { years) }\end{array}$ & NSAIDs & Canadian Health services & 3 months & No & PUB averted & $\$ 28971-25622$ & $91-86$ & 644 \\
\hline Dicerhein+standard treatment & Standard treatment & Societal & 9 months & No & Lequesne function & F2360-2272 & $2.2-1.2$ & 88 \\
\hline THR (women, 60 years) & Conventional treatment & Societal & Life & $5 \%$ & QALYs & $\$ 47649-165440$ & $4.16-2.16$ & -17121 \\
\hline THR (men, $\geqslant 85$ years) & Conventional treatment & Societal & Life & $5 \%$ & QALYs & $\$ 30580-21432$ & $4.16-2.16$ & 4754 \\
\hline THR & No THR & Societal & 1 year & No & QALYs & $\$ 9990-0$ & $0.84-0.29$ & 18164 \\
\hline THR & No THR & NHS & Life & $6 \%$ & QALYs & $£ 4804-0$ & $8.39-0$ & 573 \\
\hline THR & No THR & Irish institutional & 2 years & No & QALYs & $£ 472.06-0$ & $74.2-48.8$ & 19 \\
\hline
\end{tabular}

$\mathrm{Cl}$, total costs with intervention; $\mathrm{C} 2$, total costs with comparator; E1, effect with intervention; E2, effects with comparator; ICER, incremental cost effectiveness ratio, base case scenario; PUB, perforation, ulcer, or bleed; QALYs, quality adjusted life years. 
5. NSAIDs, at the lowest effective dose, should be added or substituted in patients who respond inadequately to paracetamol. In patients with increased gastrointestinal risk, non-selective NSAIDs plus a gastroprotective agent, or a selective COX-2 inhibitor (coxib) should be used

One systematic review has been undertaken for non-aspirin NSAIDs in the treatment of hip OA, in which 14 placebo controlled trials were reviewed. ${ }^{47}$ The ES for pain relief was 0.69 (95\% CI 0.12 to 1.26$)$ and the NNT to obtain clinical benefit over placebo was 4 ( $95 \%$ CI 3 to 6), supporting the use of NSAIDs for hip OA (table 3). However, the GI safety of NSAIDs counters their benefits. Six systematic reviews have been undertaken to assess the GI safety of NSAIDs using evidence from RCTs, cohort, and case-control studies. ${ }^{38} 48-52$ The results show that NSAIDs cause an increased risk of GI bleeding (table 4), which is dose dependent (for example, $\mathrm{OR}=2.2$ ( $95 \% \mathrm{CI} 0.8$ to 5.8 ), 3.2 ( 1.9 to 5.5 ), and 12.2 (5.6 to 26.7) for diclofenac $<75 \mathrm{mg}, 75-150 \mathrm{mg}$, and $>150 \mathrm{mg}$ a day, respectively). ${ }^{38}$

A number of strategies have been used to minimise the GI risk due to NSAIDs. Two systematic reviews demonstrated a significant reduction of GI toxicity with coxibs, ${ }^{53}{ }^{54}$ but five systematic reviews provided evidence to support the coadministration of non-selective conventional NSAIDs with gastroprotective agents such as misoprostol, double doses of $\mathrm{H}_{2}$ blockers, and proton pump inhibitors (PPIs). ${ }^{54-58}$ Table 4 presents the pooled relative risks of endoscopic gastric ulcer between coxibs or co-administration of gastroprotective agents and NSAIDs from the latest systematic review. ${ }^{54} \mathrm{~A}$ similar pattern is seen for other definitions of peptic ulcer and ulcer complications, but standard dose $\mathrm{H}_{2}$ blockers are less effective than other GI protectors, and care must be taken when using misoprostol as it causes an increase in diarrhoea $(\mathrm{RR}=1.8195 \% \mathrm{CI} 1.52 \text { to } 2.16)^{.55}$

In addition, there is concern over potential cardiovascular (CV) side effects (for example, myocardial infarction or stroke) of rofecoxib. However, a systematic review of 23 clinical trials showed that rofecoxib is only associated with a greater CV risk in comparison with naproxen ( $\mathrm{RR}=1.69,95 \%$ CI 1.07 to 2.69). The risk was not statistically significant when compared with placebo $(\mathrm{RR}=0.8495 \% \mathrm{CI} 0.51$ to 1.38 ), or non-naproxen NSAIDs ( $R R=0.79,95 \%$ CI 0.40 to 1.55)..$^{59}$ The extra CV thrombotic events with rofecoxib may therefore reflect more the antiplatelet or some other protective effects of naproxen than a side effect of rofecoxib. Further investigation of this issue is continuing.

The other important issue related to the use of coxibs or GI protectors is whether the extra benefits can balance the extra cost. Three economic evaluations of the treatment of $\mathrm{OA}$ at any site have been undertaken. ${ }^{46} 6061$ Because they all use clinical GI events (perforation, ulcer, or bleed) averted as an effectiveness outcome measure, the results may be generalisable to patients with hip OA. The results from one study showed that the ICER of coxibs versus ibuprofen was $\$ 31769.9$ for each adverse event averted for rofecoxib and $\$ 33518.5$ for celecoxib. The ICER reduced when the patients' GI risk increased, indicating that the use of coxibs is more cost effective for patients with a higher risk of GI bleeding. Similar results were obtained with GI protective agents but with a greater ICER, suggesting that co-prescription of GI protectors is the more expensive strategy (table 5).

In summary, NSAIDs are effective in relieving the pain of hip OA (category Ia). However, the GI side effects of NSAIDs offset their benefits (category Ia). Although coxibs or the addition of GI protectors (misoprostol, double doses of $\mathrm{H}_{2}$ blockers, and PPIs) to conventional NSAIDs can significantly reduce GI bleeding (category Ia), these strategies are more expensive and only cost effective in patients with greater GI risk.
6. Opioid analgesics, with or without paracetamol, are useful alternatives in patients in whom NSAIDs, including COX-2 selective inhibitors (coxibs) are contraindicated, ineffective, and/or poorly tolerated

One systematic review reported that a single dose of a combination of paracetamol and codeine increases by about $5 \%$ the analgesic strength of treatment of any type of pain, including pain due to hip OA. ${ }^{62}$ Unfortunately, the review failed to separate hip OA from other conditions. The review additionally showed that paracetamol plus codeine caused more adverse events than paracetamol alone $(R R=2.5,95 \%$ CI 1.5 to 4.2). Four RCTs were identified for hip OA, one comparing codeine with placebo ${ }^{63}$ and three comparing paracetamol plus opioid with placebo, ${ }^{64}$ paracetamol, ${ }^{65}$ or diclofenac. ${ }^{66}$ Opioid (codeine) on it own was better than placebo for pain relief ( $\mathrm{ES}=0.78,95 \% \mathrm{CI} 0.38$ to 1.18 ) and functional improvement ( $\mathrm{ES}=0.78,95 \% \mathrm{CI} 0.26$ to 1.30 ), but it also caused more adverse events $(\mathrm{RR}=1.43,95 \% \mathrm{CI} 1.09$ to 1.86). ${ }^{63}$ Although the combination of paracetamol and opioid provided better analgesia than placebo $(\mathrm{ES}=0.30,95 \% \mathrm{CI}$ 0.05 to 0.53$),{ }^{64}$ this treatment was no better than paracetamol (RR for moderate to excellent pain relief $1.27,95 \%$ CI 0.82 to $1.98)^{65}$ and was inferior to diclofenac (ES $=-0.18,95 \% \mathrm{CI}$ -0.33 to -0.04$).{ }^{66}$ More importantly, the combination caused more side effects ( $R R=7.25,95 \%$ CI 2.61 to 20.13), GI upsets, constipation ( $R R=14,95 \%$ CI 1.86 to 105.16$)$, and dizziness or drowsiness $(\mathrm{RR}=5.00,95 \% \text { CI } 1.48 \text { to } 16.92)^{64}$ and resulted in greater withdrawal rates $(\mathrm{RR}=3.57,95 \% \mathrm{CI}$ 1.92 to 6.62$)^{66}$ (table 4 ).

In summary, opioid analgesics with or without paracetamol are effective for hip OA (category Ib). However, the effect may be no better than paracetamol alone and inferior to NSAIDs (category Ib). In addition, they cause more side effects and resultant cessation of treatment (category Ia and Ib). Such evidence supports the statement and reinforces the suggestion that opioid analgesics should only be considered for patients in whom paracetamol, conventional NSAIDs or coxibs have insufficient efficacy, or in whom there are contraindications to NSAIDs/coxibs.

7. SYSADOA Iglucosamine sulphate, chondroitin sulphate, diacerhein, avocado soybean unsaponifiable, and hyaluronic acid) have a symptomatic effect and low toxicity, but effect sizes are small, suitable patients are not well defined, and clinically relevant structure modification and

pharmacoeconomic aspects are not well established The term SYSADOA covers a range of agents, including glucosamine sulphate (GS), chondroitin sulphate (CS), diacerhein, avocado soybean unsaponifiable (ASU), and hyaluronic acid (HA). The classification varies from country to country. In the UK, for example, GS and CS are classified as health food supplements and are available over the counter. A number of systematic reviews have been undertaken to support the use of oral GS ${ }^{67}{ }^{68}$ and CS. ${ }^{67}{ }^{69}$ However, none of them are specific for the hip. In the mixed trials with hip and knee OA, the pooled ES of GS versus placebo were 0.44 (95\% CI 0.24 to 0.64 ) for pain relief and 0.41 (95\% CI 0.14 to 0.69 ) for functional improvement, while those for CS were 0.78 (95\% CI 0.60 to 0.95 ) and 0.63 (95\% CI 0.32 to $0.94)$, respectively. One hip-specific placebo controlled RCT was undertaken for CS, demonstrating that CS was statistically better than placebo in reducing pain and improving function over 6 months of treatment. However, the ES could not be calculated as standard deviations were not reported. ${ }^{70}$ The systematic literature search failed to identify other levels of evidence specific for hip OA. Evidence for structure modifying effects of these two agents has not been 
established. One RCT demonstrated that intramuscular glycosaminoglycan peptide complex (now withdrawn from the market) given twice a year for 5 years had no more structural benefits than placebo for hip OA. ${ }^{71}$

Two systematic reviews ${ }^{72}$ have been undertaken for herbal treatment, including two RCTs ${ }^{74} 75$ for ASU in OA of various sites. A subgroup of patients with hip OA $(n=50)$ were available from one of the trials with a 24 week treatment period. ${ }^{75}$ The results showed a significantly greater pain relief than placebo ( $E S=0.76,95 \%$ CI 0.17 to 1.34 ). However, this was not supported by a recent trial with a larger sample size $(n=163)$ and longer treatment period ( 1 year for symptomatic outcomes and 2 years for structural changes). ${ }^{76}$ The pooled ES for pain relief and functional improvement of these two trials were not statistically significant (table 3 ). In addition, there were no structural benefits with ASU over the 2 year treatment period. ${ }^{76}$

Evidence for diacerhein is inconclusive. One multicentre RCT with 507 patients with hip OA showed that diacerhein had no more pain relief ( $\mathrm{ES}=0.00,95 \% \mathrm{CI}-0.17$ to 0.17 ) or functional improvement ( $E S=0.00,95 \% \mathrm{CI}-0.17$ to 0.17 ) than placebo over a 3 year treatment period. ${ }^{77}$ However, this study was designed to investigate structure modification rather than symptom benefit. Another RCT of 207 patients with hip or knee OA demonstrated that the combination of diacerhein and standard treatment was more effective in reducing pain ( $\mathrm{ES}=0.29,95 \%$ CI 0.05 to 0.57 ) and improving function ( $E S=0.35,95 \%$ CI 0.08 to 0.63 ) than standard treatment alone over a 6 month period, ${ }^{78}$ though data for hip OA alone was not presented.

However, regardless of efficacy diacerhein causes an increase in the incidence of side effects such as diarrhoea $(\mathrm{RR}=3.73,95 \%$ CI 2.61 to 5.32$)$, and skin rash or pruritus $(\mathrm{RR}=2.40,95 \% \mathrm{CI} 1.01$ to 5.69$) .{ }^{77}$ Nevertheless, diacerhein may slow the progression of joint space narrowing in hip $\mathrm{OA} .{ }^{77}$ The relative risk of the progression, defined as a joint space narrowing $\geqslant 0.5 \mathrm{~mm}$, during a 3 year treatment period compared with placebo was 0.84 (95\% CI 0.71 to 0.99 ), with an NNT of 10 (95\% CI 5 to 171). However, although it may be more cost effective than standard treatment in the short term without considering its long term side effects, ${ }^{78}$ the clinical benefit-risk ratio of diacerhein for patients with hip OA has yet to be confirmed.

Contrary to knee OA, there is no RCT evidence to support the use of intra-articular HA in hip OA, though three uncontrolled studies ${ }^{79-81}$ all show significant pain reduction from baseline.

In conclusion, there is no direct evidence to support the clinical benefits (pain relief and functional improvement) of
GS in hip OA, though there is category Ia evidence for OA of any joint. One RCT (category $\mathrm{Ib}$ ) demonstrates that CS effectively reduces pain and functional disability due to hip OA. The symptomatic benefits of ASU and diacerhein are inconclusive (category $\mathrm{Ib}$ ) and the evidence for HA is poor (category III). The structure modifying effect and cost effectiveness of SYSADOA have yet to be established.

\section{Intra-articular steroid injections (guided by} ultrasound or X ray) may be considered in patients with a flare that is unresponsive to analgesic and NSAIDs

Three trials have been undertaken for hip $\mathrm{OA}^{82-84}$ but only one is an RCT comparing a steroid-anaesthetic combination with anaesthetic alone. ${ }^{82}$ Only a dichotomous outcome is available from this trial and therefore the ES was not calculated. The rate ratio for pain relief was 1.18 (95\% CI 0.68 to 2.15$)$ and 0.61 ( 0.23 to 1.60$)$ at 1 month and 3 months, respectively, indicating that the combination was no better than anaesthetic alone for hip OA. Although two uncontrolled trials showed some short term ( $\leqslant 3$ months) pain reduction from intra-articular corticosteroid, ${ }^{83} 84$ the results are open to bias due to placebo effects. Thus unlike for knee OA there is no robust evidence to support the efficacy of steroid injection for hip OA, irrespective of its increased technical difficulty. Also, there are no comparative data to show increased accuracy using ultrasound or $x$ ray guidance, and no data available for the occurrence of a flare.

In conclusion, there is category Ib evidence for this statement, but the results are inconclusive and placebo controlled trials in hip OA are required.

\section{Osteotomy and joint preserving surgical procedures should be considered in young adults with symptomatic hip $O A$, especially in the presence of dysplasia or varus/valgus deformity}

Osteotomies of the pelvis and/or femoral osteotomies can alter force transmission through the hip joint and thus potentially influence clinical symptoms and the course of the OA process. Symptomatic and structural effects have been evaluated, especially in patients with acetabular dysplasia and valgus deformity of the femoral neck. As with THR, however, most published investigations are cohort studies, and we failed to identify any RCT for either symptoms or structural change. At least seven retrospective cohort studies $^{15}{ }^{16}{ }^{85-89}$ and two prospective cohort studies ${ }^{90} 91$ with follow up times ranging from 2 to 20 years have investigated both outcomes and baseline predictors relevant to the proposition. Patients showed significant improvement in

\begin{tabular}{|c|c|c|c|c|}
\hline \multirow[b]{2}{*}{ Risk factors } & \multicolumn{2}{|c|}{ Cohort studies } & \multicolumn{2}{|c|}{ Case-control studies } \\
\hline & $\begin{array}{l}\text { No of } \\
\text { studies }\end{array}$ & $\operatorname{RR}(95 \% \mathrm{Cl})$ & $\begin{array}{l}\text { No of } \\
\text { studies }\end{array}$ & OR $(95 \% \mathrm{Cl})$ \\
\hline Overall $x$ ray change ${ }^{*}$ & 4 & 2.39 (1.74 to 3.29$)$ & 1 & 1.98 (1.23 to 3.19$)$ \\
\hline Croft grade & 1 & & & \\
\hline $0 / 1$ & & 1 & & \\
\hline 2 & & $3.36(0.31$ to 38.91$)$ & & \\
\hline 3 & & 15.23 (3.29 to 70.49$)$ & & \\
\hline 4 & & 44.51 (10.04 to 197.48$)$ & & \\
\hline 5 & & 57.29 (12.12 to 270.71$)$ & & \\
\hline Pain $(\geqslant 50 \%)$ & 1 & $1.86(1.23$ to 3.88$)$ & 1 & 1.91 (1.43 to 2.56$)$ \\
\hline Lequesne function $(\geqslant 10)$ & 2 & 2.75 (1.98 to 3.82$)$ & 1 & 1.75 (1.24 to 2.48$)$ \\
\hline
\end{tabular}


clinical outcomes (pain, walking ability, and overall functional scores) and radiographic outcome after the operation. Advanced age, ${ }^{15} 91$ radiographic severity, ${ }^{1685-88}$ degree of dysplasia, ${ }^{1588}$ and radiographic deformity ${ }^{15}{ }^{16}$ at baseline were associated with worse clinical outcomes and with surgical failure, mainly defined as requirement for THR. As the vast majority of studies have been performed in young adults with at least mild or moderate symptoms (mainly hip pain) and data on the natural course of femoral and acetabular deformities is lacking, the effectiveness of osteotomy in asymptomatic patients and in different age groups has yet to be established.

Data from observational studies also support more recently advocated joint preserving surgical procedures such as arthroscopic debridement ${ }^{92}{ }^{93}$ and surgical dislocation of the hip with offset reconstruction. ${ }^{94}{ }^{95}$ Although improvement of symptoms has been reported in these studies, the lack of control groups with an alternative treatment hinders interpretation of their results.

In conclusion, evidence for osteotomy and joint preserving surgical procedures in patients with hip $\mathrm{OA}$ is sparse (category III). It appears to be a useful procedure for younger patients with painful hip dysplasia or deformity for whom THR is not yet justified. However, its effectiveness and cost effectiveness as compared with THR in patients with advanced age and/or OA stages have yet to be established.

\section{Joint replacement has to be considered in patients with radiographic evidence of hip OA who have refractory pain and disability}

Because of methodological and ethical problems, comparison of THR with placebo or standard care is not readily evaluated by an RCT. Our literature search failed to identify any placebo or standard care controlled RCT for THR. However, there are a large number of head to head comparisons between different types of prosthesis and uncontrolled follow up studies. ${ }^{96} 97$ One systematic review identified 118 uncontrolled follow up studies involving a total of 77375 patients for an average follow up period of 9.4 years (range 2-20 years). ${ }^{97}$ The percentage of patients free from pain at the end point ranged from $43.2 \%$ ( $95 \%$ CI 34 to 49 ) to $84.1 \%$ (95\% CI 46 to 100 ) depending upon the type of prosthesis. The mean reduction of Harris hip score (maximum 100, including pain 0-40, function $0-47$, motion $0-5$, and deformity $0-8$ ) from baseline ranged from $36 \%$ to $46 \%$. The revision rate, one of the major concerns for THR, was 0.18 (standard error of mean (SEM) 0.04 ) to 2.04 (SEM 0.19) per 100 person-years adjusted by age, sex, and type of hip arthritis. More information about the difference between prostheses is available, ${ }^{96}$ but this falls beyond the scope of this statement.

For concurrent comparison, better pain relief and quality of life were obtained with THR in one small Asian cohort study of THR versus non-surgical treatment. However, although in the first year THR was better than non-surgical treatment, by 5 years this benefit was reversed. ${ }^{98}$ Because the study had a very small sample size $(62 v 45)$ and no adjustment for confounders, the results are subject to bias. Two other cohort studies have been undertaken, one comparing WOMAC and SF-36 scores $^{99}$ and the other comparing survival rates ${ }^{100}$ between patients with THR and the source populations. Apart from worse functional scores, the THR group had a similar quality of life and survival rate to those of the source populations.

Whether radiographic change should be one of the criteria for THR is still open to debate. Six cohort studies ${ }^{17-22}$ (four with data available for re-analysis) and one case-control study ${ }^{101}$ demonstrated a positive relationship between radiographic severity and risk of THR (table 6). A greater risk of THR was also seen with severe pain and disability. Thus the severity of radiographic change, pain, and disability are good predictors for THR. However, whether they are independent risk factors for THR or are factors that surgeons currently use to guide the decision process is hard to determine. Nevertheless, as long as the diagnosis of OA is confirmed (most commonly by radiographic change) it has obvious validity for the severity of patient centred problems (pain, disability) to largely determine the need for major surgery.

Another important consideration for THR is whether it is cost effective compared with other treatments. Five economic evaluations of THR were identified, though one compared different prostheses ${ }^{96}$ so is not relevant to this statement. Four studies compared THR either with conventional

\begin{tabular}{ll} 
Table 7 & Future research agenda-propositions developed through three Delphi rounds \\
\hline No & Proposition \\
\hline 1 & $\begin{array}{l}\text { More RCTs of both pharmacological and non-pharmacological treatments that give outcomes } \\
\text { specific to hip OA are needed }\end{array}$ \\
2 & Biological markers for evaluation of the progression of hip OA should be further evaluated \\
3 & $\begin{array}{l}\text { Clinical predictors of response to pharmacological and non-pharmacological interventions for } \\
\text { hip OA should be determined }\end{array}$ \\
4 & $\begin{array}{l}\text { Whether long term use of SYSADOA can retard the progression of hip OA and delay joint } \\
\text { replacement should be investigated }\end{array}$ \\
5 & $\begin{array}{l}\text { RCTs of injection treatments (corticosteroid, hyaluronan) in hip OA are required } \\
7\end{array}$ \\
7 & $\begin{array}{l}\text { The most efficient and effective exercise programme for hip OA should be determined } \\
\text { effectiveness of non-surgical and surgical treatment modalities are needed }\end{array}$ \\
9 & $\begin{array}{l}\text { Agreed criteria relating to indications and timing of THR are needed } \\
\text { Prospective population based studies are required to improve our knowledge of risk factors for } \\
\text { the development and progression of hip OA }\end{array}$ \\
10 & $\begin{array}{l}\text { Newer imagining techniques (MRI, ultrasound) require validation for the diagnosis and } \\
\text { assessment of outcome in trials of hip OA }\end{array}$ \\
\hline
\end{tabular}


Table 8 Strength of recommendation

\begin{tabular}{|c|c|c|c|c|c|}
\hline \multirow[b]{2}{*}{ Intervention } & \multicolumn{3}{|l|}{ Research evidence* } & \multirow{2}{*}{$\begin{array}{l}\text { SOR based on } \\
\text { efficacy (A-D) }\end{array}$} & \multirow{2}{*}{$\begin{array}{l}\text { SOR based on all } \\
\text { evidence and clinical } \\
\text { expertise (VAS, mean } \\
\text { (SEM)) }\end{array}$} \\
\hline & Efficacy & Side effects & Cost effectiveness & & \\
\hline $\begin{array}{l}\text { Pharmacological + non-pharmacological } \\
\text { treatment }\end{array}$ & IV + & - & - & $\mathrm{D}$ & $86.94(5.82)$ \\
\hline $\begin{array}{l}\text { Treatment tailored according to risk factors, } \\
\text { severity of hip OA, and patient expectations }\end{array}$ & III + & - & - & $\mathrm{C}$ & $92.19(3.39)$ \\
\hline Education & $\mathrm{lb}+$ & - & - & A & $71.75(6.42)$ \\
\hline Exercise & - & - & - & N/A & $71.58(6.30)$ \\
\hline Insole/stick & IV+ & - & - & D & $61.72(6.91)$ \\
\hline Weight loss & III + & - & - & $\mathrm{D}$ & $68.28(5.79)$ \\
\hline Paracetamol & - & $l a-,|l| \pm(G \mid)$ & Cost saving & N/A & $79.19(3.82)$ \\
\hline NSAIDs & $\mathrm{la}+$ & $l a+,|l|+(G \mid)$ & - & A & $79.36(4.18)$ \\
\hline Coxibs & la + (Gl protection) & $\mathrm{la} \pm(\mathrm{CV})$ & $\begin{array}{l}\text { Higher GI risk } \\
\text { population }\end{array}$ & A & $79.44(3.51)$ \\
\hline Misoprostol & la + (Gl protection) & $l a+($ diarrhoea $)$ & $\begin{array}{l}\text { Higher } \mathrm{Gl} \text { risk } \\
\text { population }\end{array}$ & A & $46.06(5.62)$ \\
\hline $\mathrm{H}_{2}$ Blockers (double dose) & la + (Gl protection) & - & $\begin{array}{l}\text { High GI risk } \\
\text { population }\end{array}$ & A & $31.28(6.81)$ \\
\hline PPIs & la + (Gl protection) & - & - & $A$ & $73.86(3.97)$ \\
\hline Opioids & $\mathrm{lb}+$ & la + (any, Gl, CNS) & - & A & $43.97(4.36)$ \\
\hline Glucosamine & - & - & - & N/A & $37.06(5.03)$ \\
\hline Chondroitin & $\mathrm{lb}+$ & - & - & A & $34.44(4.76)$ \\
\hline Diacerhein & $\mathrm{lb} \pm$ & $\mathrm{lb}+$ (dyspepsia) & Short term & Inconclusive & $27.83(5.38)$ \\
\hline Avocado soybean unsaponifiable & $\mathrm{lb}-$ & - & - & Not recommended & $31.72(4.79)$ \\
\hline Hyaluronic acid & III + & - & - & C & $22.83(4.17)$ \\
\hline Intra-articular steroid & $\mathrm{lb}-$ & - & - & Not recommended & $41.47(5.74)$ \\
\hline Osteotomy & III + & - & - & C & $59.64(5.19)$ \\
\hline THR & III + & - & $\begin{array}{l}\text { Women with } \\
\text { younger age }\end{array}$ & C & $86.86(2.42)$ \\
\hline
\end{tabular}

*Evidence was categorised according to the hierarchy in table 1.

" - ", not supportive, " $+"$, supportive; " \pm ", uncertain. For example, la $+(G \mid)$ means there is category la evidence to support the statement that the treatment causes GI side effects.

SOR, strength of recommendation; VAS, visual analogue scale $(0-100 \mathrm{~mm}, 0=$ not recommended at all, $100=$ fully recommended); SEM, standard error; GI,

gastrointestinal; CV, cardiovascular; CNS, central nervous system. -, not available; N/A, not applicable owing to absent hip-specific data.

treatment ${ }^{102}$ or non-THR treatment, assuming there was no cost or effects for the non-THR group. ${ }^{97} 103104$ The results showed that THR did require additional cost to gain its additional benefits over conventional treatment or non-THR treatment (table 5). However, it was more cost effective in younger women. For example, compared with conventional treatment THR was cost saving for a woman aged 60 years (ICER -\$17121 per QALY gained), whereas it was less cost effective for a man aged more than 85 years (ICER $\$ 4,754$ per QALY gained).

Given the benefits and costs of THR, determination of the ideal point at which to perform surgery in the course of OA is crucial. A number of priority criteria have been proposed for patients awaiting THR, ${ }^{20} 103$ but none of them are universally agreed. While the importance of the degree of radiographic change remains unclear, pain and function appear the most important and agreed measures for THR and they are directly associated with postoperative outcomes. $^{21} 99105106$

In conclusion, THR is effective in hip OA in improving clinical outcomes such as pain and function (category III). In general, THR is more cost effective in younger women. Radiographic change is usually sufficient to confirm the diagnosis of hip OA, and the severity of radiographic change, as well as pain and disability are risk factors for THR. There is obvious face validity and evidence for the severity of pain and disability to be key determinants of the need for major surgery (category III).

\section{Future research agenda}

Ninety five research topics were recommended initially. Table 7 shows the 10 that were agreed eventually as the most important topics for future research according to current available research evidence and clinical practice.

\section{DISCUSSION}

This is the first comprehensive document to provide recommendations for the management of hip OA. Unlike previous guidelines that are specific for, ${ }^{107}$ or inclusive ${ }^{108}{ }^{109}$ of, hip OA, these recommendations are based both on expert opinion and research evidence, with clear separation between the two. We have employed explicit methods such as the Delphi technique to generate consensus and an evidence based medicine approach to identify and appraise the research evidence. A similar hybrid technique was used to develop the EULAR recommendations for the management of knee OA. ${ }^{67}$ However, for these recommendations on hip OA we introduced three important methodological changes.

Firstly, we did not score the quality of the studies. We had found this exercise to be unhelpful in assessing the research evidence because quality scores are subject to bias that results from the quality of reporting. For example, RCTs that appear before the CONSORT statement ${ }^{110}$ may have lower quality scores than those reported afterwards. Thus quality scores do not necessarily reflect the accuracy or credibility of a study and cannot be used to weight clinical trial results. We therefore used only the evidence hierarchy, which clearly differentiates studies according to their methodological rather than reporting qualities, to rank the quality of the evidence.

Secondly, we used the pooled effect size from the latest systematic review (or synthesised evidence if necessary) and $95 \%$ confidence intervals to present the overall estimation and the precision of the treatment effects.

Thirdly, we assessed the efficacy, side effects, and cost effectiveness of each treatment rather than just their efficacy from RCTs and applied the VAS $0-100 \mathrm{~mm}$ scale for the strength of recommendation to facilitate the multidimensional issues for each treatment. 
Of the 21 interventions included within the 10 propositions, 15 were positively supported by evidence of grades Ia to IV (table 8), but 6 of them had either no direct evidence (paracetamol, glucosamine, and exercise) or inconclusive benefits (ASU, diacerhein, and intra-articular steroid injection) for hip OA. In contrast, these treatments are effective and have been recommended for knee OA. ${ }^{67}$ More data on these interventions for hip OA are required, but the current evidence suggests that there may be true treatment differences for OA according to the site affected. Such differences support the requirement by regulatory bodies to obtain separate research evidence for the benefit of treatments at each key site of OA. Similar site-specific differences for OA are known to occur for risk factors for development and progression of OA and for the correlation between pain and structural change, reflecting the heterogeneity of the OA process. ${ }^{111}$

Although the evidence hierarchy is widely used to rank the quality of evidence, ${ }^{8}$ its value in surgical treatment and side effects has been questioned. ${ }^{112}{ }^{113}$ THR, for example, has been accepted as a clinically effective treatment for hip OA, particularly for the patient with refractory pain and disability, or for those who fail to response to conventional treatment. However, because of ethical and practical issues over blinding of the treatments, there are no placebo controlled or concurrent non-surgical controlled RCTs. The evidence to support THR comes from uncontrolled or cohort studies and is thus graded as category III, which is discordant with the high strength of support for THR when all forms of evidence, not just research evidence, are considered (table 8). Furthermore, in the absence of hip-specific data and therefore no category of evidence, strength of recommendation based on the evidence hierarchy could not be applied. Such problems challenge the current closely linked methods for categorising evidence and affording a strength of recommendation. ${ }^{112}$

To overcome this, we undertook a post hoc study by asking the committee members to mark the strength of recommendation for each intervention on a VAS (0-100 mm). Compared with the traditional grading scale for strength of recommendation, the VAS scale considers research evidence of all kinds (efficacy, safety, and cost effectiveness) and clinical expertise. More importantly, the VAS scale allows both downgrading and upgrading of the strength of recommendation, offering a different dimension from the category of evidence. For example, the strength of recommendation for NSAIDs is $79 \%$ given the highest category of evidence (Ia) for efficacy, whereas the strength of recommendation for total hip replacement is $86 \%$, although it only obtained category III evidence for efficacy (table 8).

These recommendations have several limitations. Firstly, although management of hip OA was the primary interest, for some interventions, such as paracetamol and exercise, we failed to identify any studies specific to hip OA or studies in which the data for hip OA could be separated. In this situation, we specified lack of hip-specific data but considered the evidence from mixed studies when determining the strength of recommendation. This may cause some imprecision and the values are yet to be confirmed. Secondly, the effect sizes were selected from the latest systematic review with the maximum number of the studies involved, but not necessarily the review with the best quality and relevancy. Subgroup analyses were often required, but in most cases the data were not available. Thirdly, only effect sizes for symptomatic outcomes such as pain and function were examined for efficacy. Efficacy beyond these patient centred outcomes remains unknown. Finally, the existing evidence hierarchy centres on treatment efficacy, whereas evidence for safety and cost effectiveness is best examined by designs other than RCTs and therefore requires its own specific system to judge category of evidence. In the absence of such a specific system we used the existing hierarchy, but would favour future development of an equivalent system for these other aspects of management.

In conclusion, we have developed recommendations for the management of hip OA based on both clinical practice and the best available research evidence. Fifteen of 21 interventions included within 10 key propositions have research evidence (category Ia-IV) to support their use in the management of hip OA, although they vary in their efficacy, side effect, and cost effectiveness profiles. Three interventions (paracetamol, GS, and exercise) had no hip-specific evidence and three interventions (ASU, diacerhein, and intra-articular injection) had category I evidence to show either no symptomatic benefit or inconclusive evidence for hip OA, even though these treatments are effective for knee OA. Clearly, more clinical trial data specific to hip OA are required, especially because some interventions appear to show different efficacy according to the joint site. It is hoped that wide dissemination and discussion of these recommendations within healthcare provider groups will improve knowledge and interest in the management of hip $\mathrm{OA}$ and result in higher standards of care for patients with hip OA.

\section{ACKNOWLEDGEMENTS}

We thank Bristol Myers Squibb, in particular its representative-Dr Manuela Le Bars, for financial support, and Mrs Helen Richardson and Dr Jinying Lin for logistical support.

\section{Authors' affiliations}

M Dougados, Service de Rhumatologie B, Hospital Cochin, Paris, France M Doherty, W Zhang, Academic Rheumatology, University of Nottingham, Nottingham, UK

N Arden, K Jordan, Southampton General Hospital, MRC

Environmental Epidemiology Unit, Southampton, UK

B Bannwarth, Service de Rhumatologie, Hôpital Pellegrin, Bordeaux,

France

J Bij|sma, Department of Rheumatology and Immunology, University

Hospital, Utrecht, The Netherlands

K-P Gunther, Department of Orthopaedic Surgery, University of

Dresden, Dresden, Germany

H J Hauselmann, Centre for Rheumatology and Bone Diseases, Clinic Im Park, University of Zurich, Zurich, Switzerland

G Herrero-Beaumont, Rheumatology Department, Clinique de la Conception, Madrid, Spain

P Kaklamanis, 16 Anaperon Polemon, 11521, Athens, Greece

B Leeb, Rheumatology, Stockerau Hospital, Stockerau, Austria

M Lequesne, Department of Rheumatology, Hôpital Léopold Bellan,

75014, Paris, France

S Lohmander, Department of Orthopaedics, Lund University Hospital, SE-22185, Lund, Sweden

B Mazieres, Service de Rheumatologie, Hospital de Rangueil, Toulouse, France

E Martin-Mola, Division de Rheumatologia, Hospital La Paz, Madrid, Spain

K Pavelka, Institute of Rheumatology, 12850, Praha 2, Czech Republic A Pendleton, Rheumatology, Belfast City Hospital, Belfast, UK

L Punzi, Department of Medical Sciences, University of Padova, Padova, Italy

B Swoboda, Orthopaedics, University of Erlangen-Nuremberg,

Erlangen, Germany

R Varatojo, No32B 1400-107, Lisbon, Portugal

G Verbruggen, Rheumatology Unit, UZRUG, Gent, Belgium

I Zimmermann-Gorska, Department of Rheumatology and

Rehabilitation and Internal Medicine, Poznañ, University of Medical

Sciences, Czerwca, Poland

\section{REFERENCES}

1 Felson DT. Epidemiology of hip and knee osteoarthritis. Epidemiol Rev 1988;10:1-28. 
2 Ingvarsson T, Hagglund G, Lohmander LS. Prevalence of hip osteoarthritis in Iceland. Ann Rheum Dis, 1999;58:201-7.

3 Lanyon P, Muir K, Doherty S, Doherty M. Assessment of a genetic contribution to osteoarthritis of the hip: sibling study. BMJ 2000;321:1179-83

4 Lawrence RC, Helmick CG, Arnett FC, Deyo RA, Felson DT, Giannini EH, et al. Estimates of the prevalence of arthritis and selected musculoskeletal disorders in the United States.[see comment]. Arthritis \& Rheumatism 1998:41(5):778-799.

5 Tepper S, Hochberg MC. Factors associated with hip osteoarthritis: data from the First National Health and Nutrition Examination Survey (NHANES-I). Am J Epidemiol 1993;137:1081-8.

6 Jordan KM, Arden NK, Doherty M, Bannwarth B, Biilsma JW, Dieppe P, et al. EULAR recommendations 2003: an evidence based approach to the management of knee osteoarthritis: report of a task force of the Standing Committee for International Clinical Studies Including Therapeutic Trials (ESCISIT). Ann Rheum Dis 2003;62:1145-55.

7 Pendleton A, Arden N, Dougados M, Doherty M, Bannwarth B, Bijlsma JW, et al. EULAR recommendations for the management of knee osteoarthritis: report of a task force of the Standing Committee for International Clinical Studies Including Therapeutic Trials (ESCISIT). Ann Rheum Dis 2000;59:936-44.

8 Shekelle PG, Woolf SH, Eccles M, Grimshaw J. Clinical guidelines: developing guidelines. BMJ 1999;318:593-6.

9 Hedges LV. Fitting continues models to effect size data. J Educ Stat 1982;7:245-70.

10 Cohen J. In: Statistical power analysis for the behavioral sciences, 2nd ed. Hillsdale, NJ: Lawrence Erlbaum Associates, 1988.

11 Whitehead A, Whitehead J. A general parametric approach to the metaanalysis of randomized clinical trials. Stat Med 1991;10:1665-77.

12 Cook RJ, Sackett DL. The number needed to treat: a clinically useful measure of treatment effect. BMJ 1995;310:452-4.

13 Altman DG. Confidence intervals for the number needed to treat. BMJ 1998;317:1309-12.

14 Rothman KJ. In: Modern epidemiology, 1st ed. Boston: Little Brown and Company, 1986.

15 Maistrelli GL, Gerundini M, Fusco U, Bombelli R, Bombelli M, Avai A. Valgus-extension osteotomy for osteoarthritis of the hip. Indications and long-term results. J Bone Joint Surg Br 1990;72:653-7.

16 Ohashi H, Hirohashi K, Yamano Y. Factors influencing the outcome of Chiari pelvic osteotomy: a long-term follow-up. J Bone Joint Surg $\mathrm{Br}$ 2000:82:517-25.

17 Birrell F, Afzal C, Nahit E, Lunt M, Macfarlane GJ, Cooper C, et al. Predictors of hip joint replacement in new attenders in primary care with hip pain. Br J Gen Pract 2003;53(486):26-30.

18 Dougados M, Gueguen A, Nguyen M, Berdah L, Lequesne M, Mazieres B, et al. Requirement for total hip arthroplasty: an outcome measure of hip osteoarthritis? J Rheumatol 1999;26:855-61

19 Maillefert JF, Gueguen A, Nguyen M, Berdah L, Lequesne M, Mazieres B, et al. Relevant change in radiological progression in patients with hip osteoarthritis. I. Determination using predictive validity for total hip arthroplasty. Rheumatology (Oxford) 2002;41:142-7.

20 Maillefert JF, Gueguen A, Nguyen M, Berdah L, Lequesne M, Mazieres B, et al. A composite index for total hip arthroplasty in patients with hip osteoarthritis. J Rheumatol 2002;29:347-52.

21 Nilsdotter AK, Aurell Y, Siosteen AK, Lohmander LS, Roos HP. Radiographic stage of osteoarthritis or sex of the patient does not predict one year outcome after total hip arthroplasty. Ann Rheum Dis 2001;60:228-32.

22 Vinciguerra C, Gueguen A, Revel M, Heuleu JN, Amor B, Dougados M. Predictors of the need for total hip replacement in patients with osteoarthritis of the hip. Rev Rhum Engl Ed 1995;62:563-70.

23 Mancuso CA, Sculco TP, Salvati EA. Patients with poor preoperative functional status have high expectations of total hip arthroplasty. J Arthroplasty 2003;18:872-8.

24 Haddad FS, Garbuz DS, Chambers GK, Jagpal TJ, Masri BA, Duncan CP. The expectations of patients undergoing revision hip arthroplasty. J Arthroplasty 2001;16:87-91.

25 Superio-Cabuslay E, Ward MM, Lorig KR. Patient education interventions in osteoarthritis and rheumatoid arthritis: a meta-analytic comparison with nonsteroidal antiinflammatory drug treatment. Arthritis Care Res 1996;9:292-301.

26 Warsi A, LaValley MP, Wang PS, Avorn J, Solomon DH. Arthritis selfmanagement education programs: a meta-analysis of the effect on pain and disability. Arthritis Rheum 2003;48:2204-13.

27 Giraudet-Le Quintrec JS, Coste J, Vastel L, Pacault V, Jeanne L, Lamas JP, et al. Positive effect of patient education for hip surgery: A randomized trial. Clin Orthop Relat Res 2003;414:112-20.

28 Brosseau L, MacLeay L, Robinson V, Wells G, Tugwell P. Intensity of exercise for the treatment of osteoarthritis. Cochrane Database Syst Rev 2003; 2:CD004259

29 Fransen M, McConnell S, Bell M. Therapeutic exercise for people with osteoarthritis of the hip or knee. A systematic review. J Rheumatol 2002; 29: 1737-45.

30 Fransen $M$, McConnell S, Bell M. Exercise for osteoarthritis of the hip or knee. Cochrane Database Syst Rev 2003;(3):CD004286

31 Puett DW, Griffin MR. Published trials of nonmedicinal and noninvasive therapies for hip and knee osteoarthritis. Ann Intern Med 1994;121:133-40.

32 van Baar ME, Assendelft WJ, Dekker J, Oostendorp RA, Bijlsma JW. Effectiveness of exercise therapy in patients with osteoarthritis of the hip or knee: a systematic review of randomized clinical trials. Arthritis Rheum 1999;42:1361-9.

33 Lievense AM, Bierma-Zeinstra SM, Verhagen AP, van Baar ME, Verhaar JA, Koes BW. Influence of obesity on the development of osteoarthritis of the hip: a systematic review. Rheumatology (Oxford) 2002;41:1155-62.

34 Towheed TE, Judd MJ, Hochberg MC, Wells G. Acetaminophen for osteoarthritis. Cochrane Database Syst Rev 2003;(2):CD004257.

35 Zhang W, Jones A, Doherty M. Does paracetamol (acetaminophen) reduce the pain of osteoarthritis? A meta-analysis of randomised controlled trials. Ann Rheum Dis 2004;63:901-7. doi:10.1136/ard.2003.018531 [Published Online First 5 March 2004].

36 Garcia Rodriguez LA, Hernandez-Diaz S. Relative risk of upper gastrointestinal complications among users of acetaminophen and nonsteroidal anti-inflammatory drugs. Epidemiology 2001;12:570-6.

37 Rahme E, Pettitt D, LeLorier J. Determinants and sequelae associated with utilization of acetaminophen versus traditional nonsteroidal antiinflammatory drugs in an elderly population. Arthritis Rheum 2002;46:3046-54.

38 Lewis SC, Langman MJS, Laporte J-R, Matthres NS, Rawlins MD, Wiholm B-E. Dose-response relationships between individual nonaspirin nonsteroidal anti-inflammatory drugs (NSAIDs) and serious upper gastrointestinal bleeding: a meta-analysis based on individual patient data. $\mathrm{Br} \mathrm{J}$ Clin Pharmacol 2002;54:320-6

39 Jerussi TP, Caubet J-F, McCray JE, Handley DA. Clinical endoscopic evaluation of the gastroduodenal tolerance to (R)- ketoprofen, (R)flurbiprofen, racemic ketoprofen, and paracetamol: a randomized, singleblind, placebo-controlled trial. J Clin Pharmacol 1998;38(suppl 2):19-24S.

40 Lanza FL, Codispoti JR, Nelson EB. An endoscopic comparison of gastroduodenal injury with over-the-counter doses of ketoprofen and acetaminophen. Am J Gastroenterol 1998:93:1051-4.

41 Muller P, Simon B, Weise D, Dammann HG. Endoscopic studies on the gastric tolerance following 6 days treatment of paracetamol and acetylsalicylic acid. A placebo-controlled double-blind-study in the healthy volunteers. [In German.] Arzneimittelforschung 1990;40:316-18.

42 Barrett BJ. Acetaminophen and adverse chronic renal outcomes: an appraisal of the epidemiologic evidence. Am J Kidney Dis 1996;28(suppl 1):14-19.

43 Rexrode KM, Buring JE, Glynn RJ, Stampfer MJ, Youngman LD, Gaziano JM. Analgesic use and renal function in men. JAMA 2001;286:315-21.

44 Zhang W. A benefit-risk assessment of caffeine as an analgesic adjuvant. Drug Safety 2001;24:1127-42.

45 Fored CM, Ejerblad E, Lindblad P, Fryzek JP, Dickman PW, Signorello LB, et al. Acetaminophen, aspirin, and chronic renal failure. N Engl J Med 2001;345:1801-8

46 Kamath CC, Kremers HM, Vanness DJ, O'Fallon WM, Cabanela RL, Gabriel SE. The cost-effectiveness of acetaminophen, NSAIDs, and selective COX-2 inhibitors in the treatment of symptomatic knee osteoarthritis. Value Health 2003;6:144-57

47 Towheed T, Shea B, Wells G, Hochberg M. Analgesia and non-aspirin, nonsteroidal anti-inflammatory drugs for osteoarthritis of the hip. [Review] [17 refs]. Cochrane Database Syst Rev 2000;(2):CD000517.

48 Bollini P, Garcia Rodriguez LA, Perez Gutthann S, Walker AM. The impact of research quality and study design on epidemiologic estimates of the effect of nonsteroidal anti-inflammatory drugs on upper gastrointestinal tract disease. Arch Intern Med 1992;152:1289-95.

49 Gabriel SE, Jaakkimainen L, Bombardier C. Risk for serious gastrointestinal complications related to use of nonsteroidal anti-inflammatory drugs. A meta-analysis. Ann Intern Med 1991;115(10):787-96.

50 Garcia Rodriguez LA. Variability in risk of gastrointestinal complications with different nonsteroidal anti-inflammatory drugs. Am J Med 1998; 104:30-4S.

51 Ofman JJ, MacLean CH, Straus WL, Morton SC, Berger ML, Roth EA, et al. A metaanalysis of severe upper gastrointestinal complications of nonsteroidal antiinflammatory drugs. J Rheumatol 2002;29:804-12.

52 Tramer MR, Moore RA, Reynolds DJM, McQuay HJ. Quantitative estimation of rare adverse events which follow a biological progression: a new model applied to chronic NSAID use. Pain 2000;85:169-82.

53 Deeks JJ, Smith LA, Bradley MD. Efficacy, tolerability, and upper gastrointestinal safety of celecoxib for treatment of osteoarthritis and rheumatoid arthritis: systematic review of randomised controlled trials. BMJ 2002;325:619-23.

54 Rostom A, Dube C, Jolicoeur E, Boucher M, Joyce J. Gastroduodenal ulcers associated with the use of non-steroidal anti-inflammatory drugs: a systematic review of preventive pharmacological interventions. Ottawa: Canadian Coordinating Office for Health Technology Assessment, 2004 (Technology overview 12.).

55 Capurso L, Koch M. [Prevention of NSAID-induced gastric lesions: H2 antagonists or misoprostol? A meta-analysis of controlled clinical studies]. [In Italian]. Clin Ter 1991;139:179-89.

56 Leandro G, Pilotto A, Franceschi M, Bertin T, Lichino E, Di Mario F. Prevention of acute NSAID-related gastroduodenal damage: a meta-analysis of controlled clinical trials. Dig Dis Sci 2001;46:1924-36.

57 Rostom A, Wells G, Tugwell P, Welch V, Dube C, McGowan J. The prevention of chronic NSAID induced upper gastrointestinal toxicity: $A$ cochrane collaboration metaanalysis of randomized controlled trials. J Rheumatol 2000;27:2203-14.

58 Shield MJ. Diclofenac/misoprostol: novel findings and their clinical potential. J Rheumatol 1998:25(supp 51):31-41.

59 Konstam MA, Weir MR, Reicin A, Shapiro D, Sperling RS, Barr E, et al. Cardiovascular thrombotic events in controlled, clinical trials of rofecoxib. Circulation 2001;104:2280-8. 
60 Gabriel SE, Jaakkimainen RL, Bombardier C. The cost-effectiveness of misoprostol for nonsteroidal antiinflammatory drug-associated adverse gastrointestinal events. Arthritis Rheum 1993;36:447-59.

61 Pellissier JM, Straus WL, Watson DJ, Kong SX, Harper SE. Economic evaluation of rofecoxib versus nonselective nonsteroidal anti-inflammatory drugs for the treatment of osteoarthritis. Clin Ther 2001;23:1061-79.

62 de Craen AJM, Di Giulio G, Lampe-Schoenmaeckers, Kessels AGH, Kleijnen $J$. Analgesic efficacy and safety of paracetamol-codeine combinations versus paracetamol alone: a systematic review. BMU 1996:313:321-5.

63 Peloso PM, Bellamy N, Bensen W, Thomson GT, Harsanyi Z, Babul N, et al. Double blind randomized placebo control trial of controlled release codeine in the treatment of osteoarthritis of the hip or knee. J Rheumatol 2000;27:764-71.

64 Emkey R, Rosenthal N, Wu SC, Jordan D, Kamin M. Efficacy and safety of tramadol/acetaminophen tablets (Ultracet) as add-on therapy for osteoarthritis pain in subjects receiving a COX-2 nonsteroidal antiinflammatory drug: a multicenter, randomized, double-blind, placebocontrolled trial. J Rheumatol 2004:31:150-6.

65 Kjaersgaard-Andersen P, Nafei A, Skov O, Madsen F, Andersen HM Kroner K, et al. Codeine plus paracetamol versus paracetamol in longer-term treatment of chronic pain due to osteoarthritis of the hip. A randomised, double-blind, multi-centre study. Pain 1990;43:309-18.

66 Parr G, Darekar B, Fletcher A, Bulpitt CJ. Joint pain and quality of life; results of a randomised trial. Br J Clin Pharmacol 1989;27:235-42.

67 McAlindon TE, LaValley MP, Gulin JP, Felson DT. Glucosamine and chondroitin for treatment of osteoarthritis: a systematic quality assessment and meta-analysis.[comment]. JAMA 2000;283(11):1469-75.

68 Towheed TE, Anastassiades TP, Shea B, Houpt J, Welch V, Hochberg MC. Glucosamine therapy for treating osteoarthritis. Cochrane Database Syst Rev 2001; (1):CD002946

69 Leeb BF, Schweitzer H, Montag K, Smolen JS. A metaanalysis of chondroitin sulfate in the treatment of osteoarthritis. J Rheumatol 2000;27:205-11.

70 Conrozier T, Vignon E. Die wirkung von chondroitisulfat bei der behandlung der huftgelenksarthrose eine doppelblindstudie gegen placebo. Lit Rheumato 1992; 14:69-75.

71 Pavelka K, Gatterova J, Gollerova V, Urbanova Z, Sedlackova M, Altman RD. A 5-year randomized controlled, double-blind study of glycosaminoglycan polysulphuric acid complex (Rumalon) as a structure modifying therapy in osteoarthritis of the hip and knee. Osteoarthritis Cartilage 2000;8:335-42

72 Little CV, Parsons T. Herbal therapy for treating osteoarthritis. Cochrane Database Syst Rev 2001 ; (1):CD002947.

73 Long L, Soeken K, Ernst E. Herbal medicines for the treatment of osteoarthritis: a systematic review. Rheumatology (Oxford) 2001;40:779-93.

74 Blotman F, Maheu E, Wulwik A, Caspard H, Lopez A. Efficacy and safety of avocado/soybean unsaponifiables in the treatment of symptomatic osteoarthritis of the knee and hip. A prospective, multicenter, three-month, randomized, double-blind, placebo-controlled trial. Rev Rhum Engl Ed 1997;64:825-34.

75 Maheu E, Mazieres B, Valat JP, Loyau G, Le Loet X, Bourgeois P, et al. Symptomatic efficacy of avocado/soybean unsaponifiables in the treatmen of osteoarthritis of the knee and hip: a prospective, randomized, doubleblind, placebo-controlled, multicenter clinical trial with a six-month treatment period and a two-month followup demonstrating a persistent effect. Arthritis Rheum 1998:41:81-91.

76 Lequesne M, Maheu E, Cadet C, Dreiser RL. Structural effect of avocado/ soybean unsaponifiables on joint space loss in osteoarthritis of the hip. Arthritis Rheum 2002;47:50-8.

77 Dougados M, Nguyen M, Berdah L, Mazieres B, Vignon E, Lequesne M. Evaluation of the structure-modifying effects of diacerein in hip osteoarthritis: ECHODIAH, a three-year, placebo-controlled trial. Arthritis Rheum 2001;44:2539-47.

78 Fagnani $F$, Bouvenot G, Valat JP, Bardin T, Berdah L, Lafuma A, et al. Medico-economic analysis of diacerein with or without standard therapy in the treatment of osteoarthritis. Pharmacoeconomics 1998;13:135-46.

79 Brocq O, Tran G, Breuil V, Grisot C, Flory P, Euller-Ziegler L. Hip osteoarthritis: short-term efficacy and safety of viscosupplementation by hylan G-F 20. An open-label study in 22 patients. Joint Bone Spine 2002;69:388-91.

80 Vad VB, Sakalkale D, Sculco TP, Wickiewicz TL. Role of hylan G-F 20 in treatment of osteoarthritis of the hip joint. Arch Phys Med Rehabil 2003;84:1224-6.

81 Conrozier T, Bertin P, Mathieu P, Charlot J, Bailleul F, Treves R, et al. Intraarticular injections of hylan G-F 20 in patients with symptomatic hip osteoarthritis: an open-label, multicentre, pilot study. Clin Exp Rheumatol 2003;21:605-10.

82 Flanagan J, Casale FF, Thomas TL, Desai KB. Intra-articular injection for pain relief in patients awaiting hip replacement. Ann $R$ Coll Surg Engl 1988:70:156-7.

83 Plant MJ, Borg AA, Dziedzic K, Saklatvala J, Dawes PT. Radiographic patterns and response to corticosteroid hip injection. Ann Rheum Dis 1997;56:476-80.

84 Waseem M, Sadiq S, Gambhir AK, Lim J, Maxwell S, Bamford DJ. Safety and efficacy of intra-articular injection of the hip. Hip International 2002; 12:378-82.
85 Murphy S, Deshmukh R. Periacetabular osteotomy: preoperative radiographic predictors of outcome. Clin Orthop Relat Res 2002;405:168-74.

86 Takatori Y, Ninomiya S, Nakamura S, Morimoto S, Moro T, Nagai I. Longterm results of rotational acetabular osteotomy in young patients with advanced osteoarthrosis of the hip. J Orthop Sci 2000:5:336-41.

87 Takatori Y, Ninomiya S, Nakamura S, Morimoto S, Moro T, Nagai I, et al. Long-term results of rotational acetabular osteotomy in patients with slight narrowing of the joint space on preoperative radiographic findings. J Orthop Sci $2001 ; 6: 137-40$

88 Tönnis D, Arning A, Bloch M, Heineche A, Kalohschmidt K. Triple pelvic osteotomy. J Pediatr Orthop 1994;3:53-67.

89 Yasunaga Y, Takahashi K, Ochi M, Ikuta Y, Hisatome T, Nakashiro J, et al. Rotational acetabular osteotomy in patients forty-six years of age or older: Comparison with younger patients. J Bone Joint Surg Am 2003;85:266-72.

90 Hasegawa Y, Iwase T, Kitamura S, Yamauchi KK, Sakano S, Iwata H. Eccentric rotational acetabular osteotomy for acetabular dysplasia: follow-up of one hundred and thirty-two hips for five to ten years. J Bone Joint Surg Am 2002;84:404-10.

91 Siebenrock KA, Leunig M, Ganz R. Periacetabular osteotomy: the Bernese experience. J Bone Joint Surg Am 2001;83:449-55.

92 Helenius I, Tanskanen P, Haapala J, Niskanen R, Remes V, Mokka R, et al. Hip arthroscopy in osteoarthritis. A review of 68 patients. Ann Chirurg Gynaecol $2001 ; 90: 28-31$.

93 Margheritini F, Villar RN. The efficacy of arthroscopy in the treatment of hip osteoarthritis. Chir Organi Mov 1999;84:257-61.

94 Beck M, Leunig M, Parvizi J, Boutier V, Wyss D, Ganz R. Anterior femoroacetabular impingement: part II. Midterm results of surgical treatment. Clin Orthop Relat Res 2004;418:67-73.

95 Ganz R, Gill TJ, Gautier E, Ganz K, Krugel N, Berlemann U. Surgical dislocation of the adult hip: a technique with full access to the femoral head and acetabulum without the risk of avascular necrosis. J Bone Joint Surg $\mathrm{Br}$ 2001;83:1119-24.

96 Faulkner A, Kennedy LG, Baxter K, Donovan J, Wilkinson M, Bevan G. Effectiveness of hip prostheses in primary total hip replacement: a critical review of evidence and an economic model. Health Technol Assess 1998;2:1-133.

97 Fitzpatrick R, Shortall E, Sculpher M, Murray D, Morris R, Lodge M, et al. Primary total hip replacement surgery: a systematic review of outcomes and modelling of cost-effectiveness associated with different prostheses. Health Technol Assess 1998;2:1-64.

98 Kawasaki M, Hasegawa Y, Sakano S, Torii Y, Warashina H. Quality of life after several treatments for osteoarthritis of the hip. J Orthop Sci 2003;1:32-5.

99 Nilsdotter A-K, Petersson IF, Roos EM, Lohmander LS. Predictors of patient relevant outcome after total hip replacement for osteoarthritis: a prospective study. Ann Rheum Dis 2003;62:923-30.

100 Visuri T, Pulkkinen P, Turula KB, Paavolainen P, Koskenvuo M. Life expectancy after hip arthroplasty. Case-control study of 1018 cases of primary arthrosis. Acta Orthop Scand 1994;65:9-11

101 Dolin SJ, Williams AC, Ashford N, George J, Pereira L, Perello A. Factors affecting medical decision-making in patients with osteoarthritis of the hip: Allocation of surgical priority. Disabil Rehabil 2003;25:771-7.

102 Chang RW, Pellisier JM, Hazen GB. A cost-effectiveness analysis of total hip arthroplasty for osteoarthritis of the hip. JAMA 1996;275:858-65.

103 O'Shea K, Bale E, Murray P. Cost analysis of primary total hip replacement Irish Med J 2002;95:177-80.

104 Rorabeck CH, Bourne RB, Laupacis A, Feeny D, Wong C, Tugwell P, et al. A double-blind study of 250 cases comparing cemented with cementless total hip arthroplasty. Cost-effectiveness and its impact on health-related quality of life. Clin Orthop Relat Res 1994;298:156-64.

105 NIH consensus conference. Total hip replacement. NIH Consensus Development Panel on Total Hip Replacement. JAMA 1995;273:1950-6.

106 Maillefert JF, Gueguen A, Nguyen M, Berdah L, Lequesne M, Mazieres B, et al. A composite index for total hip arthroplasty in patients with hip osteoarthritis. J Rheumatol 2002;29:347-52

107 Hochberg MC, Altman RD, Brandt KD, Clark BM, Dieppe PA, Griffin MR, et al. Guidelines for the medical management of osteoarthritis: Part I. Osteoarthritis of the hip. Arthritis Rheum 1995;38:1535-40.

108 Kwoh CK, Anderson LG, Greene JM, Johnson DA, O'Dell JR, Robbins ML, et al. Guidelines for the management of rheumatoid arthritis: 2002 updateAmerican College of Rheumatology Subcommittee on Rheumatoid Arthritis Guidelines. Arthritis Rheum 2002;46:328-46.

109 Scott DL. Guidelines for the diagnosis, investigation and management of osteoarthritis of the hip and knee. J R Col Physicians Lond 1993;27:391-6.

110 Begg C, Cho M, Eastwood S, Horton R, Moher D, Olkin I, et al. Improving the quality of reporting of randomized controlled trials: the CONSORT statement. JAMA 1996;276:637-9.

111 Felson DT, Lawrence RC, Dieppe PA, Hirsch R, Helmick CG, Jordan JM, et al. Osteoarthritis: new insights-Part 1: The disease and its risk factors. Ann Intern Med 2000; 133:635-46.

112 Black N. Evidence-based surgery: a passing fad? World J Surg 1999;23:789-93.

113 Black N. Why we need observational studies to evaluate the effectiveness of health care. BMJ 1996;312:1215-18. 